\title{
PRIMARY BREAST TUBERCULOSIS DIAGNOSED BY FINE NEEDLE ASPIRATION CYTOLOGY - A RARE CASE REPORT.
}

\author{
Dilip Chandra Barman, Achintya Narayan Ray, Pasan Lal Sherpa, Aniket Halder
}

1. Assistant Professor, Department of Pathology, North Bengal Medical College. West Bengal.
2. Associate Professor, Department of Medicine, North Bengal Medical College. West Bengal.
3. Assistant Professor, Department of Medicine, North Bengal Medical College. West Bengal.
4. Post Graduate Trainee, Department of Pathology, North Bengal Medical College. West Bengal.

\section{CORRESPONDING AUTHOR}

Dr. Dilip Chandra Barman, Department of Pathology, North Bengal Medical College, Sushrutanagar, Darjeeling, West Bengal, India. E-mail: dilip77d@gmail.com Ph: 00919474327035

ABSTRACT: Primary Breast Tuberculosis is an uncommon disease entity even in developing countries where pulmonary and extrapulmonary tuberculosis are very common. Breast Tuberculosis presents clinically as non-healing ulcer or breast abscess but may even mimic Breast Carcinoma. Even imaging studies like mammography are of little help in diagnosing these cases precisely. As such, only fine needle aspiration cytology (FNAC) or histopathological examination following biopsy can provide a definitive diagnosis. Since Anti-tubercular therapy (ATT) is the mainstay of treatment of these lesions, a prompt diagnosis needs to be done. We present here a case of Primary Breast Tuberculosis which was initially mistaken as breast abscess and failed to heal with repeated courses of antibiotic therapy. However, the case was correctly diagnosed by FNAC. The patient was then put on ATT for six months and was cured.

KEY WORDS: Breast, Fine needle aspiration cytology, Tuberculosis.

INTRODUCTION: Primary breast tuberculosis is very rare; only a few cases have been reported till date with an incidence of less than $1 \%$ of all breast lesions in western countries and $4 \%$ of all breast lesions in endemic countries like India. ${ }^{[1,2]}$ Young, lactating multiparous women are commonly affected and can present as an abscess or as a unilateral, painless breast mass. ${ }^{[1,2]}$ It is comparatively common in underdeveloped countries due to poor hygiene and poor sanitation. Moreover immune suppressive condition like acquired immune deficiency virus (AIDS) plays an additive role. It is treated as extrapulmonary tuberculosis with anti tubercular therapy (ATT) for six months under the Revised National Tuberculosis Control Programme (RNTCP) in India.

CASE REPORT: A 40 year old female presented with a vague lump near the areola of left breast since 8 months [Figure 1]. On examination there was a solitary, firm, tender immobile vague nodular lump measuring $3 \mathrm{~cm} \times 2 \mathrm{~cm}$. There was an ulcer in the overlying skin from which there was mild discharge on pressing. There was no fever, cough or any past history of tuberculosis. There was no cervical or axillary lymphadenopathy. Initial laboratory tests included complete haemogram, chest X-ray and Mantoux test. The complete haemogram was within normal limits and no lung lesion was identified on chest X-ray. Mantoux test was negative. The lesion was clinically suspected as a breast abscess and treated with antibiotics. But, when the lesion failed 
to heal even after repeated courses of antibiotics, an Ultrasonography (USG) and Fine needle aspiration cytology (FNAC) was advised from the lesion.

USG showed an ill-defined heterogenous lump beneath the ulcer measuring $27 \mathrm{~mm} \times 19$ $\mathrm{mm}$ [Figure 2]. Rest of the breast was normal. USG-guided FNAC was done from the lesion by a 23 gauge needle fitted to a 10cc syringe. The aspirate was blood mixed granular and smears were prepared from the aspirate on clean blood slides. The wet-fixed smears were stained with Haematoxylin \& Eosin (H/E) stain and the air-dried smears were stained with Leishman's stain. Ziehl- Neelsen (ZN) stain was also done for demonstration of Acid-fast bacilli (AFB). Microscopic examination showed numerous epithelioid cell granulomas, multinucleated Langhans type giant cell with focal areas of necrosis. AFB was found in ZN stain [Figure 3]. Thus, a diagnosis of tuberculous mastitis was made.

The patient was immediately put on Anti tubercular therapy (ATT) and was followed up. After two months of therapy, there was dramatic improvement of the lesion. After the completion of the six month course of ATT, the lesion was completely healed with a residual scar mark [Figure 4].

DISCUSSION: Tuberculosis (TB) of breast was first described by Copper in 1829 as the scrofulous swelling of the bosom.[3] Only a few clinical case reports have been reported from the Indian subcontinent inspite of the high prevalence of the other forms of TB in this region. ${ }^{[4,5]}$ The disease usually occurs in reproductive age (20-50 years). Breast tuberculosis is a clinically significant disease entity as it may mimic different inflammatory lesions and even breast carcinoma, clinically \& radiologically; only FNAC or biopsy can diagnose it. Breast tuberculosis involves usually the upper outer quadrant or central part of the breast. Studies have shown that most of the patients with primary breast TB do not have any pulmonary or systemic symptoms. $[1,2]$

Tewari et al (2005) has recently reclassified breast TB into three groups, namely, nodular, disseminated and abscess varieties. [2] The new classification was done taking into consideration the changes seen in the clinical presentation of tuberculosis over the last two decades. Sclerosing tubercular mastitis, tuberculous mastitis obliterans and acute milliary tubercular mastitis are rare nowadays and of historical importance only, whereas tubercular breast abscess is more frequently encountered. The latter is common among young females and represents up to $30 \%$ of the cases in recent publications.[2,6] The nodular form usually presents as a localised slowly growing mass that progress to involve the skin, which may ulcerate or form sinuses. Histologically, this form of breast TB is characterised by extensive caseation and little fibrosis. $[7,8,9]$

CONCLUSION: We have intended to present this case because primary breast tuberculosis is rare even in developing countries like India, where other forms of tuberculosis are endemic. Tubercular infection of breast can be easily mistaken as chronic breast abscess or breast carcinoma where the typical clinical prodrome of tuberculosis is usually absent. Imaging studies are also not helpful in providing a definitive diagnosis. In this regard, proper clinical history along with FNAC or biopsy can help in prompt and accurate diagnosis.

\section{REFERENCES :}

1. Akcakaya A, Eryilmaz R, Sahin M, Ozkan O.Tuberculosis of the breast. The breast journal 2005; 11: 85-6. 
2. Tewari M, Shukla HS. Breast tuberculosis; diagnosis, clinical features and management. Indian J Med Res 2005; 122: 103-10.

3. Cooper A. Illustration of the diseases of the breast. London: Longman, Rees and Co; 1829.

4. Banerjee A, Green B, Burke M. Tuberculous and granulomatous mastitis. Practioner 1989; 233: 754-7.

5. Tan KK, Tan TH. Tuberculosis of the breast. Singapore Med J 1988; 29: 271-5.

6. Shukla US. Kumar S. Benign breast disorders in non western populations; Part U-Benign breast disorders in India. World J Surg 1989; 13: 746-9.

7. Raw N. Tuberculosis of the breast . Br Med J 1924; 1: 657-8.

8. Mukherjee P, George M, Maheshwari HB, Rao CP. Tuberculosis of the breast. J Indian Med Assoc 1974; 62: 410-20.

9. Dubey MM, Agarwal S. Tuberculosis of the breast. J Indian Med Assoc 1968; 51: 358-9.

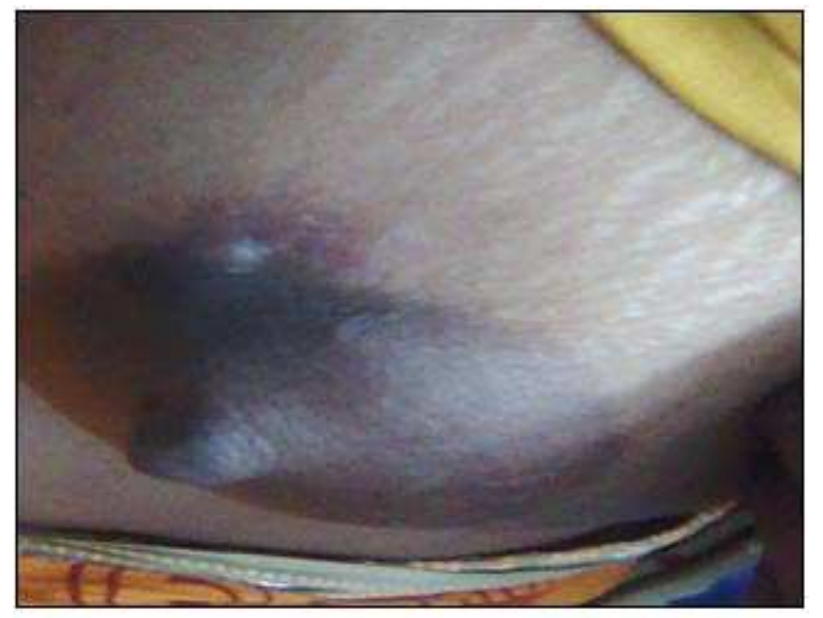

Fig 1 Photograph of the breast lesion at presentation. The ulcer over the overlying skin.

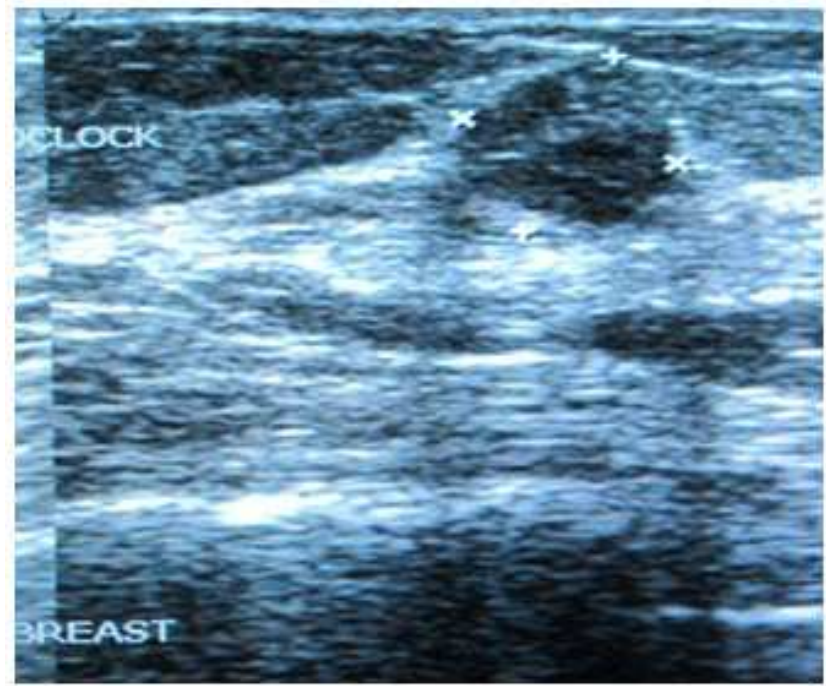

[Figure 2]

USG showed heterogenous mass beneath the ulcer of left breast. 

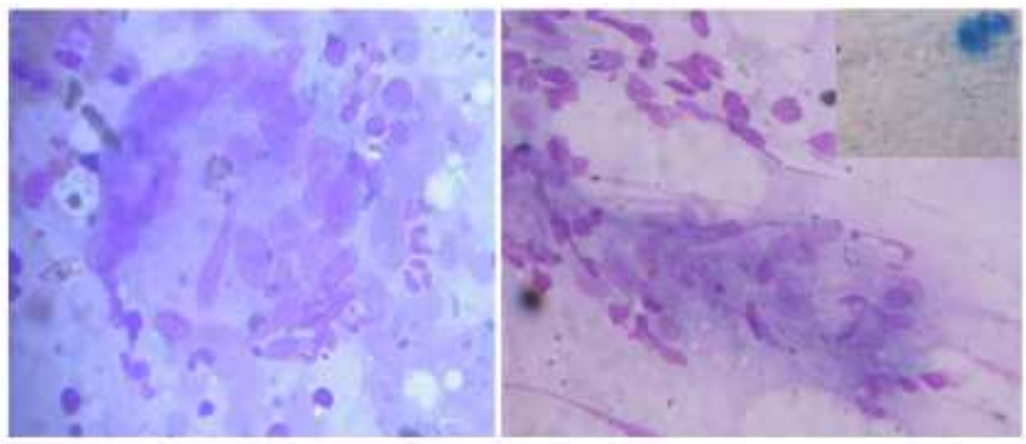

[Figure 3] Photomicrograph of the multinucleated horse-shoe shaped Langhans Type giant cell [left] and epithelioid cell granuloma [right], Leishman's Stain, 400X. [Inset: AFB seen in ZN stain, 1000X].

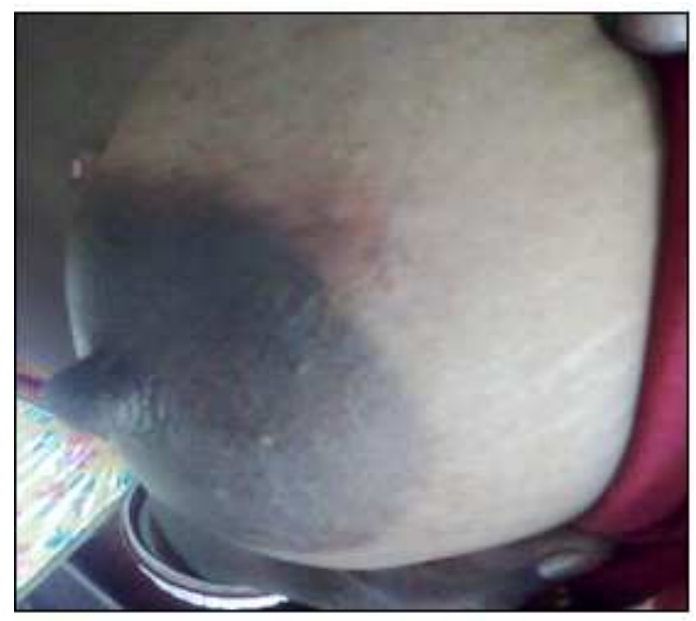

[Figure 4] Photograph of the breast lesion after completion of ATT. Only the healed scar is visible. 